\title{
Escherichia coli Isolated from Diabetic Foot Osteomyelitis: Clonal Diversity, Resistance Profile, Virulence Potential, and Genome Adaptation
}

\author{
Alexi Lienard ${ }^{1, \dagger}$, Michel Hosny ${ }^{2,+}{ }^{\oplus}$, Joanne Jneid ${ }^{2} \mathbb{D}$, Sophie Schuldiner ${ }^{3}$, Nicolas Cellier ${ }^{4}$, Albert Sotto ${ }^{5}$, \\ Bernard La Scola ${ }^{2}{ }^{\mathbb{D}}$, Jean-Philippe Lavigne ${ }^{6, *(1)}$ and Alix Pantel ${ }^{6}$ \\ 1 VBIC, INSERM U1047, Université de Montpellier, UFR de Médecine, 30908 Nîmes CEDEX 2, France \\ ALIENARD@ch-bassindethau.fr \\ 2 Aix-Marseille Université UM63, Institut de Recherche pour le Développement IRD 198, Assistance Publique \\ Hôpitaux de Marseille (AP-HM), Microbes, Evolution, Phylogeny and Infection (MEФI), \\ Institut Hospitalo-Universitaire (IHU) Méditerranée Infection, 13005 Marseille, France; \\ michosny@hotmail.com (M.H.); joannejneid@hotmail.com (J.J.); bernard.la-scola@univ-amu.fr (B.L.S.) \\ 3 VBIC, INSERM U1047, Université de Montpellier, Service des Maladies Métaboliques et Endocriniennes, \\ CHU Nîmes, 30029 Nîmes CEDEX 09, France; sophie.schuldiner@chu-nimes.fr \\ 4 Service d'Orthopédie, CHU Nîmes, 30029 Nîmes CEDEX 09, France; nicolas.cellier@chu-nimes.fr \\ 5 VBIC, INSERM U1047, Université de Montpellier, Service des Maladies Infectieuses et Tropicales, \\ CHU Nîmes, 30029 Nîmes CEDEX 09, France; albert.sotto@chu-nimes.fr \\ 6 VBIC, INSERM U1047, Université de Montpellier, Service de Microbiologie et Hygiène Hospitalière, \\ CHU Nîmes, 30029 Nîmes CEDEX 09, France; alix.pantel@chu-nimes.fr \\ check for \\ updates \\ * Correspondence: jean.philippe.lavigne@chu-nimes.fr \\ + These authors contributed equally to this work.
}

Citation: Lienard, A.; Hosny, M.; Jneid, J.; Schuldiner, S.; Cellier, N.; Sotto, A.; La Scola, B.; Lavigne, J.-P.; Pantel, A. Escherichia coli Isolated from Diabetic Foot Osteomyelitis: Clonal Diversity, Resistance Profile, Virulence Potential, and Genome Adaptation. Microorganisms 2021, 9 , 380. https://doi.org/10.3390/ microorganisms 9020380

Academic Editor: Ines Arana

Received: 28 January 2021

Accepted: 11 February 2021

Published: 13 February 2021

Publisher's Note: MDPI stays neutral with regard to jurisdictional claims in published maps and institutional affiliations.

Copyright: (c) 2021 by the authors. Licensee MDPI, Basel, Switzerland. This article is an open access article distributed under the terms and conditions of the Creative Commons Attribution (CC BY) license (https:// creativecommons.org/licenses/by/ $4.0 /)$.
Abstract: This study assessed the clonal diversity, the resistance profile and the virulence potential of Escherichia coli strains isolated from diabetic foot infection (DFI) and diabetic foot osteomyelitis (DFOM). A retrospective single-centre study was conducted on patients diagnosed with E. coli isolated from deep DFI and DFOM at Clinique du Pied Diabétique Gard-Occitanie (France) over a two-year period. Phylogenetic backgrounds, virulence factors (VFs) and antibiotic resistance profiles were determined. Whole-genome analysis of $E$. coli strains isolated from same patients at different periods were performed. From the two-years study period, 35 E. coli strains isolated from 33 patients were analysed; $73 \%$ were isolated from DFOM. The majority of the strains belonged to the virulent B2 and D phylogenetic groups (82\%). These isolates exhibited a significant higher average of VFs number than strains belonging to other groups $(p<0.001)$. papG2 gene was significantly more detected in strains belonging to B2 phylogroup isolated from DFI compared to DFOM $(p=0.003)$. The most prevalent antibiotic resistance pattern was observed for ampicillin (82\%), cotrimoxazole (45\%), and ciprofloxacin (33\%). The genome analysis of strains isolated at two periods in DFOM showed a decrease of the genome size, and this decrease was more important for the strain isolated at nine months (vs. four months). A shared mutation on the putative acyl-CoA dehydrogenase-encoding gene aidB was observed on both strains. E. coli isolates from DFOM were highly genetically diverse with different pathogenicity traits. Their adaptation in the bone structure could require genome reduction and some important modifications in the balance virulence/resistance of the bacteria.

Keywords: adaptation; diabetic foot osteomyelitis; Escherichia coli; resistance; whole-genome sequencing; virulome

\section{Introduction}

Diabetic foot ulcers (DFUs) are estimated to affect 19 to $34 \%$ of all diabetic individuals during their lifetime [1]. Infection of these ulcers is frequent (40-80\%), representing a major cause of mortality and morbidity [2]. Diabetic Foot Osteomyelitis (DFOM) is 
a common complication of DFU and/or diabetic foot infections (DFI) [3]. In Western developed countries, DFI are mainly caused by aerobic Gram-positive cocci (especially Staphylococcus aureus). However, in deep ulcers or wounds occurring in a patient who has been previously treated by antibiotics, DFI/DFOM are more often polymicrobial, including aerobic Gram-negative and obligate anaerobic bacteria. Furthermore, recent epidemiological studies from subtropical countries described a considerably higher predominance of Gram-negative bacilli (Pseudomonas aeruginosa and Enterobacteriaceae) in these geographical parts of the world [4].

The characterization of Escherichia coli isolates from skin and soft tissue infection (SSTIs) have been previously published [5,6]. However, this description still remains poor from DFIs, whereas E. coli is a main pathogenic Gram-negative bacteria isolated from these ulcers [7-11]. This pathogen is one of the most important agents of extraintestinal infections, with the potential to cause infections in almost any anatomical site. Extraintestinal Pathogenic E. coli (ExPEC) strains possess virulence factors (VFs) encoding genes that cause infections. These genes are located on plasmids or, more frequently, on the chromosome. On the chromosome, they are typically found in a specific region called Pathogenicity Island (PAI). Such VFs allow E. coli to bind to human cells (P-fimbriae, S-fimbriae), to survive in the human body (siderophores) and to invade the host by damaging human cells and tissues (toxins such as hemolysin and cytotoxic necrotizing factors) [12]. This combination of VFs determines if $E$. coli can cause infection [13]. The host characteristics also play an important role. Studies have described that the host compromised, including the older age and urinary tract abnormalities, allows comparatively low virulence E. coli strains to cause urosepsis [14].

In this study, we described E. coli strains isolated from DFOM/deep DFI, determined their phylogenetic relationships, virulence profiles, antibiotic resistance, and genome adaptation for two persistent infections.

\section{Materials and Methods}

\subsection{Study Design}

This study was approved by the institutional review board (IRB-2017-04) and carried out in accordance with the Helsinki Declaration as revised in 2000 [15]. From the 1 January 2015 to the 31 December 2016, we retrospectively enrolled all diabetic patients managed in the Clinique de Pied Diabétique Gard Occitanie at the Nîmes University Hospital (France) for deep DFI and suspected DFOM. Patients were included if they had not received any antibiotic agents in the previous week. All wounds were assessed for presence and severity of infection by a trained diabetologist using the PEDIS classification of the IWGDF consensus conference [2]. Patients were suspected of having osteomyelitis of the foot if they had at least two of the following clinical criteria: (i) a wound whose duration was $\geq 2$ weeks located above an underlying bony prominence, with an area $>2 \mathrm{~cm}^{2}$ or a depth $>3 \mathrm{~mm}$, (ii) a positive probe-to-bone test and (iii) abnormalities consistent with the diagnosis of osteomyelitis either on plain X-rays, radionuclide procedures (three-phase bone scan and/or labelled leukocyte imaging), or magnetic resonance imaging. DFOM was definitively diagnosed when one or more bacteria was isolated from bone biopsies. Epidemiological and clinical data were gathered for all patients.

After wound debridement, samples for bacterial culture were obtained by transcutaneous bone or tissue biopsy performed by a trained orthopaedist using the procedure previously described [3]. All the samples were immediately sent to the Department of Microbiology.

\subsection{Conventional Microbiological Method}

Tissue and bone samples were cultured following the European guidelines [16]. Additionally, a Schaedler broth was inoculated by bone biopsy. All the media were incubated for 14 days. Genus and species of all the isolates were determined using the Vitek ${ }^{\circledR}$ MS system (bioMérieux, Marcy-l'Etoile, France). Susceptibility to antimicrobial agents was tested by 
the disk diffusion method (BioRad, Marnes La Coquette, France) on Mueller-Hinton agar with or without horse blood, according to the recommendations of the EUCAST-SFM 2019 (http:/ / www.sfm-microbiologie.org (accessed on 28 January 2021)). In addition, Minimum Inhibitory Concentrations (MICs) of carbapenems (ertapenem, imipenem, and meropenem) were determined by E-test method (bioMérieux). MIC of colistin was determined using microbroth dilution (Umic ${ }^{\circledR}$, Biocentric, France). The MICs were interpreted as specified by the CA-SFM/EUCAST criteria. E. coli resistant to the third generation cephalosporins were classified as multidrug-resistant organism (MDRO).

\subsection{Analysis of Clonality of the Strains}

The genetic relationship between the E. coli strains was evaluated by repetitive sequence-based PCR (rep-PCR) using the DiversiLab ${ }^{\circledR}$ strain typing system (bioMérieux). Results were interpreted with DiversiLab web-based software (bioMérieux) using the Pearson correlation and the modified Kullback-Leibler method. Isolates with identical strain patterns were considered indistinguishable if the similarity percentage was $\geq 95 \%$.

Multi-Locus Sequence Typing (MLST) analysis was performed using the Achtman MLST scheme (pubmlst/org/mlst). Seven housekeeping genes (edk, fumH, gyrB, icd, $m d h$, recA and purA) were amplified according to this protocol.

\subsection{Phylogenetic Grouping}

Phylogenetic grouping of the E. coli strains was determined by a PCR-based method developed by Clermont et al. [17] identifying one of the eight phylogenetic groups (A, B1, $\mathrm{B} 2, \mathrm{C}, \mathrm{D}, \mathrm{E}, \mathrm{F}$, clade I) using a combination of four DNA markers (chuA, yjaA, arpA genes, and TspE4.C2).

\subsection{Molecular Characterization of Main Resistance Genes}

Total DNA of cultures was extracted using the EZ1 DNA Tissue kit on the BioRobot EZ1 extraction platform (Qiagen, Courtaboeuf, France). Genes encoding the most clinically prevalent Extended Spectrum $\beta$-Lactamases (ESBLs) $\left(b l a_{\mathrm{TEM}}, b l a_{\mathrm{SHV}}\right.$, and $\left.b l a_{\mathrm{CTX}-\mathrm{M}}\right)$ were detected by PCR using specific primers and confirmed by sequencing the PCR products, as described previously $[18,19]$. A multiplex PCR was used for the detection of plasmidic $b l a_{a m p c}$ genes [20]. Genetic characterization of the quinolone resistance-determining region (QRDR) (gyrA, gyrB, parC and parE mutations) was performed by $\mathrm{PCR}$ and gene sequencing [21].

\subsection{Virulence Genotyping}

The E. coli strains were tested by PCR for the presence of a panel of 20 genes encoding known VFs [21-25]: 1) Fimbriae and/or adhesins: fimH (D-mannose-specific adhesin, type 1 fimbriae), papG1, pap G2, papG3 (Gal( $\alpha 1-4)$ Gal-specific pilus tip adhesin molecule), papA (major structural subunit of $\mathrm{P}$ fimbrial shaft; defines $\mathrm{F}$ antigen), papC (pilus assembly; central region of pap operon), papE, sfaS, focG (S fimbriae and F1C fimbriae), afa/draBC (Dr family adhesin); 2) Toxins: cnf1 (cytotoxic necrotizing factor-1), hlyA (hemolysin); 3) Iron uptake: iut $A$ (ferric aerobactin receptor (iron uptake: transport), iroN (catecholate (salmochelin) siderophore receptor), fyuA (ferric yersiniabactin uptake receptor); 4) Protectins: $k p s M T I I$ (capsule synthesis), traT (surface exclusion, serum survival (outer membrane protein)); 5) Others: $u s p$ (uropathogenic-specific protein (bacteriocin)), malX (a marker for pathogenicityassociated island marker from archetypal uropathogenic strain CFT073), and ompT (outer membrane protein (protease) $\mathrm{T}$ ).

If a strain was positive for two or more markers including papAH and/or $p a p C$, $s f a / f o c D E, a f a / d r a B C, k p s M T I I$, and iut $A$, this isolate belonged to ExPEC [26].

\subsection{Whole-Genome Analysis and Single-Nucleotide Polymorphism Identification}

E. coli strains $(n=4)$ isolated from same patients at different periods were sequenced. Whole Genome Sequencing (WGS) was performed with an Illumina MiSeq sequencing sys- 
tem (Illumina, San Diego, CA, USA) using paired-end (PE) read libraries (PE250) prepared by Nextera XT DNA Library Prep Kit (Illumina) following the manufacturer's protocol. Rax reads were processed using FastQC (v.0.11.7) to assess data quality. The Cutadapter tool (v.1.16) implemented in Python (v.3.5.2) was used to remove residual PCR primers and to filter low quality bases (Q_score $<30)$ and short reads $(<150 \mathrm{bp})$. The filtered trimmed reads were included in the downstream analysis. Obtained reads were mapped against $E$. coli IAI39 genome (GenBank accession number: GCA_000026345.1), using the CLC genomics workbench 7 (Qiagen Inc., Valencia, CA, USA). The assembled contigs were processed by Prokka software for microbial genome annotation [27]. The VirulenceFinder-1.5 server (https:/ / cge.cbs.dtu.dk/services/VirulenceFinder (accessed on 28 January 2021)) was used to infer virulence encoding genes from genomes sequences. Antimicrobial resistance genes and plasmid replicons were obtained from ABRIcate with the ResFinder database on assembled genomes [28,29] and PlasmidFinder database [30]. Toxin-antitoxin encoding ORF were extracted from genomes annotations. Targeted genomes were aligned binary against wild-type strains using the MAFFT software, as following NECS21/NECS50 and NECR70/NECR107 [31]. SNP calls were made from the PE library raw reads. The REALPHY tool was used to identify the closest relationships between the strains and the different $E$. coli reference genomes deposited in GenBank. For SNP analysis, we employed the following software: SNP-sites for variants calling [32] and SnpEff (v.4.3T) for SNP annotation in coding regions [33]. SNP annotations of affected genes were searched within wild-type genomes and their effects were classified depending mutations impacts. Genes affected by stop gain mutations were searched for in the Uniprot database for virulence classification. Finally, PAIs were predicted within implicated genomes using IslandViewer 4 database [34].

\subsection{Statistical Analysis}

The analyses were merely descriptive: data were given as numbers and percentages. For each VF, comparisons between the different phylogroups were evaluated by using Fisher's exact test. A $p$-value $\leq 0.05$ was considered as reflecting statistical significance. Statistical analyses were performed using GraphPad Prism 6.0 (GraphPad Software, La Jolla, CA, USA).

\section{Results}

\subsection{Baseline Characteristics and Microbiological Considerations}

From the two-year study period, 340 patients were hospitalized for DFI and included into the study. A total of 704 strains were isolated (Supplementary Table S1) from 362 samples, corresponding to a mean number of 1.94 isolate per sample. A polymicrobial infection was present in 206 samples ( 7 with 5 bacteria, 45 with 4 bacteria, 77 with 3 bacteria, 77 with 2 bacteria). In 104 samples, infection was monomicrobial and 52 cultures were negative. Aerobic Gram-positive cocci were predominant (46.5\% of all species) with S. aureus as the most commonly isolated pathogen $(n=162)$ accounting for $23.0 \%$ of the species $(44.5 \%$ of the Gram-positive cocci). Streptococcus spp. represented $11.1 \%$ of all species $(n=78)$. Aerobic Gram-negative bacilli accounted for $28.8 \%$ of the microorganisms $(n=203)$. Among them, Enterobacteriaceae were the most frequent bacteria ( $25.7 \%$ of all species) especially E. coli, which represented $19.9 \%$ of enterobacteria. Non-fermentative Gram-negative bacilli were rather uncommon with notably Pseudomonas spp. representing exclusively $1 \%$ of all species. Finally, the anaerobes represented $19.0 \%$ of the species. Finegoldia spp. and Bacteroides spp. were the most commonly isolated anaerobes ( $14.9 \%$ of all species).

As previously mentioned, E. coli was the main enterobacteria detected $(n=36)$ and were isolated in 34 patients from the bacterial culture of their infected wound. One strain was not investigated because no subculture could be obtained after congelation. We included 33 patients. Four samples (12\%) were monomicrobial, $14(42 \%)$ were bi-microbial, the others $(15,46 \%)$ contained three or more microorganisms. 
The demographic and clinical characteristics of the 33 patients definitively included are shown in Table 1.

Table 1. Demographic and clinical characteristics of the studied patients.

\begin{tabular}{|c|c|}
\hline Characteristics & Total * \\
\hline Number of patients (total $n$ ) & 33 \\
\hline Median Age (range), years & $63.0(36-96)$ \\
\hline Male $/$ female, $n(\%)$ & $28(84.8) / 5(15.2)$ \\
\hline Type 1 /type 2 diabetes mellitus & $4(12.1) / 29(87.9)$ \\
\hline Mean diabetes duration (years) & $16.7 \pm 9.1$ \\
\hline $\mathrm{HbA}_{1 \mathrm{c}}(\%)$, mean & $6.50 \pm 0.89$ \\
\hline \multicolumn{2}{|l|}{ Cardiovascular disease } \\
\hline Absence & $2(6.7)$ \\
\hline Coronary heart disease & $10(30.3)$ \\
\hline Peripheral arterial disease & $31(93.9)$ \\
\hline Neuropathy & $33(100)$ \\
\hline Nephropathy & $17(51.5)$ \\
\hline Diabetic retinopathy & $14(42.4)$ \\
\hline \multicolumn{2}{|l|}{ Lifestyle factors } \\
\hline Hypertension & $17(51.5)$ \\
\hline Obesity & $5(15.1)$ \\
\hline Dyslipidemia & $18(54.5)$ \\
\hline First wound/Recurrence & $14(42.4) / 19(57.6)$ \\
\hline Osteomyelitis & $24(72.7)$ \\
\hline \multicolumn{2}{|l|}{ PEDIS infection classification } \\
\hline Grade 3 (Moderate) & $32(97.0)$ \\
\hline Grade 4 (severe) & $1(3.0)$ \\
\hline
\end{tabular}

* Values median and interquartile ranges (25th to 75 th percentile) or numbers and percentages into brackets. HbA1c: glycated hemoglobin.

Most of the included patients were male (82\%) with a median age of 66.5 years (36-96). Thirty-two DFI (97.1\%) were classified as grade 3 and one as grade 4 (2.9\%). In 16 patients $(48.5 \%)$, the current wound was the first episode of ulceration. The majority of the wounds $(73 \%)$ were associated with osteomyelitis. Two patients had a persistent infection with two E. coli isolated at 4 months (NECS21-NECS50) and 9 months apart (NECR70-NECR107).

\subsection{Antimicrobial Susceptibility of E. coli}

The in vitro activities of antimicrobial agents against the $33 \mathrm{E}$. coli isolates are presented in Table 2. Three strains (9\%) expressed an extended spectrum $\beta$-lactamase (ESBL), which confers resistance to third generation cephalosporins.

ESBL were carried by bla $a_{\mathrm{CTX}-\mathrm{M}-1}$ gene (associated with a bla $a_{\mathrm{TEM}-1}$ gene) for two strains, and by bla CTX-M-9 gene for one strain. Four strains $(12 \%)$ were resistant to piperacillin/ tazobactam. All studied isolates were susceptible to ertapenem and imipenem. Amikacin was the most effective aminoglycoside (only 1 resistant strain). The most prevalent antimicrobial resistance was observed for ampicillin (82\% of the strains), cotrimoxazole (45\%) and amoxicillin/clavulanic acid (42\%). Resistance to ciprofloxacin was found in 11 strains $(33 \%)$ due to mutations in gyr $A$ (at codon 83 (Ser $83 \rightarrow$ Tyr) and/or codon 87 (Asp87 $\rightarrow$ Asn) and parC genes (at codon 80 (Ser $80 \rightarrow$ Ile) and/or codon $84($ Glu84 $\rightarrow$ Ala)). 
Table 2. Resistance of the 35 E. coli strains isolated from deep diabetic foot infections and diabetic foot osteomyelitis.

\begin{tabular}{|c|c|c|c|c|c|c|}
\hline \multirow{3}{*}{ Antibiotics } & \multicolumn{6}{|c|}{ Phylogroups, $n$ (\%) } \\
\hline & B1 & B2 & $\mathrm{C}$ & D & $\mathbf{I}$ & Total \\
\hline & $3(8.6)$ & $19(54.3)$ & $2(5.7)$ & $10(28.6)$ & $1(2.9)$ & 35 (100) \\
\hline AMX & $3(100)$ & $13(68)$ & $2(100)$ & $9(90)$ & 1 & $28(80)$ \\
\hline $\mathrm{AMC}$ & $2(67)$ & $10(53)$ & $1(50)$ & $3(30)$ & 0 & $16(45.7)$ \\
\hline $\mathrm{TZP}$ & $1(33)$ & $2(11)$ & $0(0)$ & $1(10)$ & 0 & $4(12)$ \\
\hline CTX & $1(33)$ & $2(11)$ & $0(0)$ & $0(0)$ & 0 & $3(8.6)$ \\
\hline CAZ & $1(33)$ & $2(11)$ & $0(0)$ & $0(0)$ & 0 & $3(8.6)$ \\
\hline FOX & $0(0)$ & $0(0)$ & $0(0)$ & $0(0)$ & 0 & $0(0)$ \\
\hline IPM & $0(0)$ & $0(0)$ & $0(0)$ & $0(0)$ & 0 & $0(0)$ \\
\hline OFX & $3(100)$ & $3(15.8)$ & $1(50)$ & $4(40)$ & 1 & $12(34.3)$ \\
\hline CIP & $3(100)$ & $3(15.8)$ & $1(50)$ & $4(40)$ & 1 & $12(34.3)$ \\
\hline GEN & $1(33)$ & $0(0)$ & $0(0)$ & $0(0)$ & 0 & $1(2.9)$ \\
\hline TOB & $1(33)$ & $0(0)$ & $0(0)$ & $0(0)$ & 0 & $1(2.9)$ \\
\hline AMK & $0(0)$ & $0(0)$ & $0(0)$ & $0(0)$ & 0 & $0(0)$ \\
\hline FOS & $0(0)$ & $0(0)$ & $0(0)$ & $0(0)$ & 0 & $0(0)$ \\
\hline SXT & $2(67)$ & $4(21)$ & $1(50)$ & $3(30)$ & 1 & $11(31.4)$ \\
\hline COL & $0(0)$ & $0(0)$ & $0(0)$ & $0(0)$ & 0 & $0(0)$ \\
\hline
\end{tabular}

AMX, amoxicillin; AMC, amoxicillin + clavulanic acid; TZP, piperacillin/tazobactam; CTX, cefotaxime; CAZ, ceftazidime; FOX, cefoxitin; IPM, imipenem; OFX, ofloxacin; CIP, ciprofloxacin; GEN, gentamicin; TOB, tobramycin, AMK, amikacin; FOS, fosfomycin; SXT, cotrimoxazole; COL, colistin.

\subsection{Clonality Analysis of the E. coli}

The rep-PCR showed a great diversity of the E. coli while the strains were grouped in 27 different rep-PCR patterns (Figure 1). Only two profiles included three isolates: patterns IX ( $n=3$; phylogroup B2), XIX $(n=3$; B2). The residual patterns contained two isolates (4 rep-PCR patterns: VIII, XXIII, XXV, XXVII) or single isolates (21 rep-PCR patterns). Among the isolates harboring the same rep-PCR pattern, we observed that the strains isolated at two periods in two patients were identical in each case (patterns XXIII and XXVII).

The Achtman MLST scheme also showed the great diversity of the isolates with 18 ST detected. The ST95 was the most important (6 isolates; 3 concerning pattern XIX) followed by ST597 ( 5 isolates; including pattern XXIII), ST73 (4 isolates and including pattern IX), and ST31 (4 isolates, including pattern XXVII). No isolate belonged to the international O25b:H4-ST131 clone. 


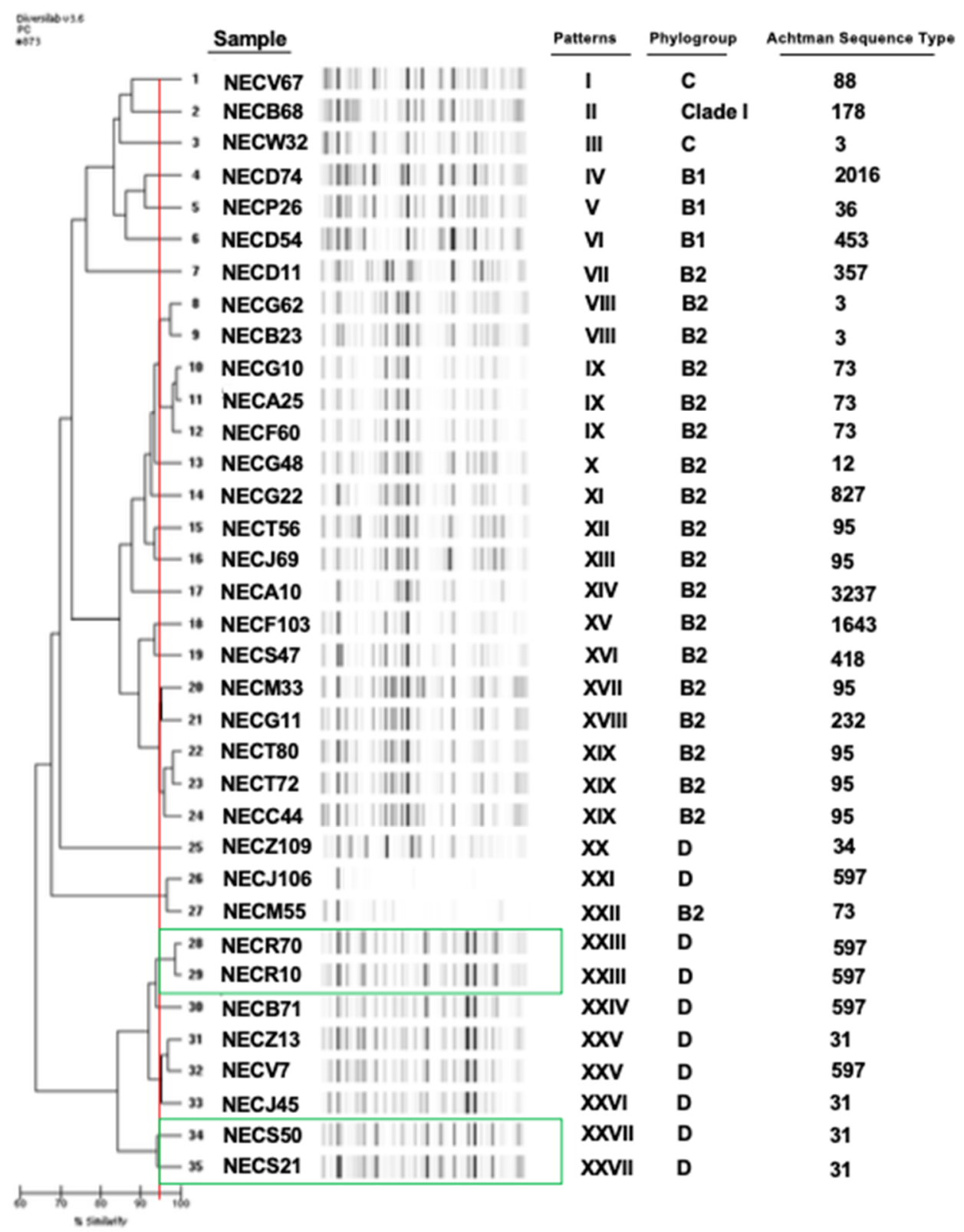

Figure 1. Genetic diversity of Escherichia coli strains isolated from diabetic foot infections using DiversiLab method, MultiLocus Sequence Typing and phylogrouping. In green, the strains isolated at two periods in a same patient (Patient 1 , NECR70/NECR10; Patient 2, NECS50/NECS21).

\subsection{Virulence Profiles of E. coli}

The distribution of phylogroups and virulence factors are presented in Table 3.

The most prevalent phylogenetic group was B2 $(54 \%, n=19)$ followed by D phylotype $(28 \%, n=10), \mathrm{B} 1(9 \%, n=3), \mathrm{C}(6 \%, n=2)$, and clade I $(3 \%, n=1)$. The majority of the strains (71\%) could be defined as ExPEC according to the definition [26]. The average number of VFs was 10.1 ( \pm 3.7$)$. Strains belonging to group B2 exhibited a significant higher average of VFs number than strains belonging to B1 (11.8 vs 5.0, $p<0.001$ ). 
Table 3. Distribution of virulence factors in the E. coli isolated from diabetic foot osteomyelitis (DFOM) and deep diabetic foot infection (dDFI).

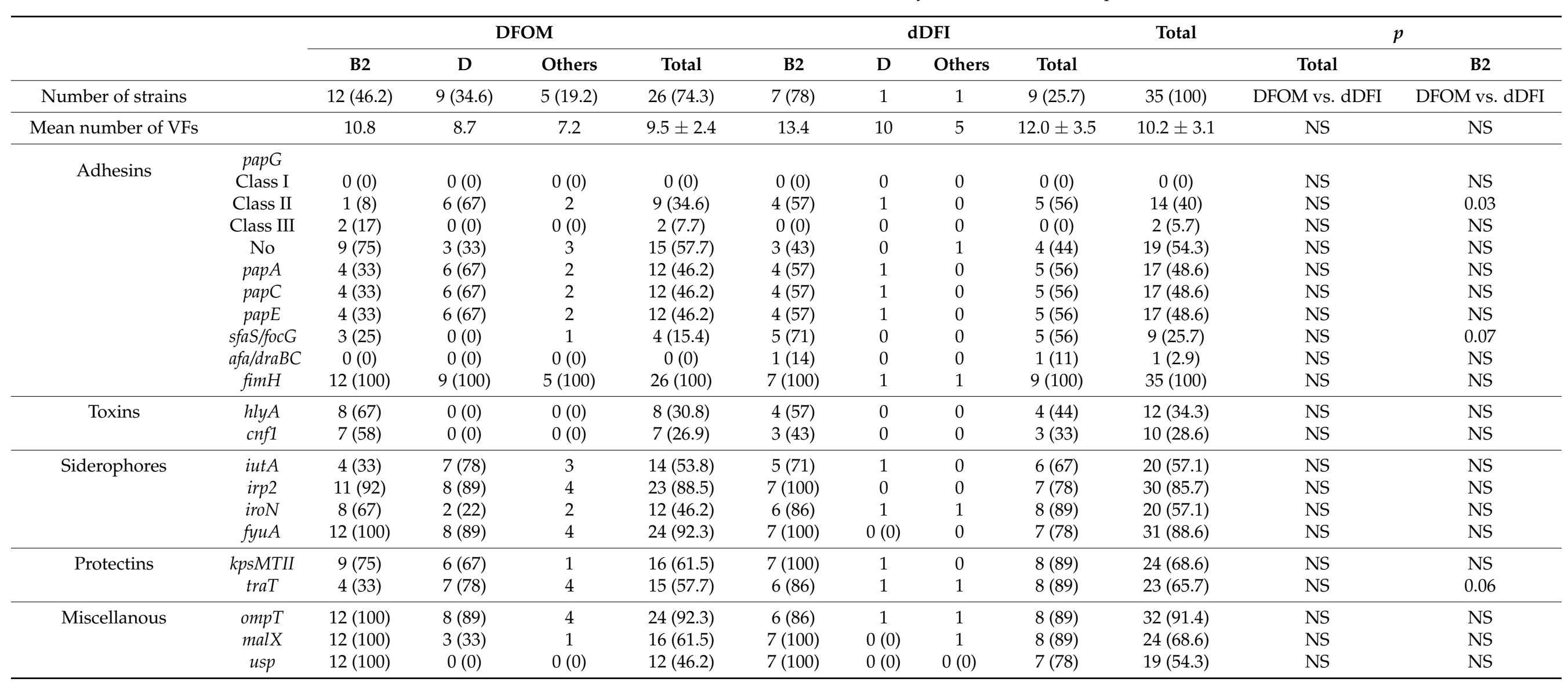


NS, not significant.Concerning the genes encoding the adhesins, all the strains harboured fimH. Half of the strains presented papA, papC, papE genes (17 isolates, 49\%). papG2 was most frequently detected compared to papG3 (14 (40\%) vs. 2 (5.7\%) isolates, respectively). No strain harboured the papG1 gene. Concerning the genes encoding toxins, $h l y A$ and $c n f 1$ genes were detected in $12(35 \%)$ and 10 isolates (28\%), respectively. The majority of isolates presented the iron uptake and protectins encoding genes: fyuA $(n=31,88 \%)$, $\operatorname{kpsMTII}(n=24,69 \%), \operatorname{traT}(n=23,66 \%)$, iroN $(n=20,57 \%)$ and iut $A(n=20,57 \%)$. Finally, the protease-encoding gene (ompT) was detected in almost all the strains $(n=32,91 \%)$. As we mentioned below, the strains belonging to B2 phylogroup possessed the majority of the VFs screened. Interestingly, afa1 ( $n=1,5 \%$ of the strains belonging to B2), pap 33 ( $n=2$, $11 \%)$, cnf1 $(n=10,53 \%)$, hlyA $(n=12,63 \%)$, and $u s p(n=19,100 \%)$ genes were exclusively detected in this group of strains. Moreover, all of these strains harboured fimH, usp, and malX genes.

The distribution of strains isolated from DFOM was similar of that of the deep foot infections suggesting no particular tropism of bone for a clone: $46 \%$ belonged to the phylogroup B2, 34\% to the D, 8\% to B1 and C, 4\% to clade I. Strains involved in DFOM exhibited less VFs than strains involved in deep DFI (9.5 vs. 12.1, respectively) even if this difference was not significant (Table 3). Concerning the distribution of VFs, we could note that papG3 gene were exclusively detected in DFOM and the isolates found in bone biopsies presented more irp2 and fyuA genes (Table 3). On the other side, papG2 gene was significantly more detected in strains belonging to B2 phylogroup isolated from deep foot infections compared to DFOM $(p=0.003)$. A trend was also noted for $s f a S$ and traT genes more frequently present in deep DFI ( $p=0.07$ and 0.06 , respectively).

Finally, we noticed that the most resistant strain (harbouring ESBL, resistance to aminoglycosides, fluroquinolones, and cotrimoxazole) was also the strain with the lower number of VFs and belonged to the B1 phylogroup. The other ESBL-producing isolates belonged to B2 phylogroups and harboured an important arsenal of VFs (8 and 14, respectively). These isolates were equally distributed between DFOM and deep DFI (2 vs. 1, respectively). The most susceptible strains to antibiotics more commonly belonged to the B2 phylogroup (6 strains $/ 6)$.

\subsection{E. coli Genome Analysis}

In this study, two patients with DFOM harboured E. coli at two time periods. Following the result of rep-PCR indicating that these isolates were clonal, we sequenced the genomes of the strains (Table 4).

Table 4. Escherichia coli genomic features isolated from DFOM of two patients at two periods.

\begin{tabular}{ccccccccc}
\hline Strain & Patients & $\begin{array}{c}\text { Date of } \\
\text { Isolation } \\
\text { (Dy/Mo/Y) }\end{array}$ & $\begin{array}{c}\text { Genome } \\
\text { Coverage } \\
\text { (fold) }\end{array}$ & $\begin{array}{c}\text { Sequence } \\
\text { Type }\end{array}$ & $\begin{array}{c}\text { Genome } \\
\text { Size (bp) }\end{array}$ & $\begin{array}{c}\text { G+C } \\
\text { Content (\%) }\end{array}$ & $\begin{array}{c}\text { Coding \% } \\
\text { ORFs }{ }^{\text {a }}\end{array}$ \\
\hline NECS21 & 57 y, DT2 ${ }^{\mathrm{b}}$ & $11 / 03 / 2015$ & $101 \times$ & ST3 & $4,468,950$ & $51.1 \%$ & $87.4 \%$ & 4284 \\
NECS50 & & $21 / 07 / 2015$ & $151 \times$ & & $4,455,576$ & $51.1 \%$ & $86.5 \%$ & 4258 \\
\hline NECR70 & 67 y, DT2 & $22 / 10 / 2015$ & $105 \times$ & ST494 & $4,528,137$ & $51.1 \%$ & $87.2 \%$ & 4312 \\
NECR107 & & $30 / 07 / 2016$ & $98 \times$ & & $4,440,985$ & $51.2 \%$ & $86.4 \%$ & 4267 \\
\hline
\end{tabular}

${ }^{\mathrm{a}}$ Open-Reading Frame; ${ }^{\mathrm{b}}$ DT2, diabetes mellitus Type 2.

We confirmed that the strains were identical in each case for the first and the second sample. Moreover, virulence encoding genes and toxin/antitoxin ORFs were identified in all isolates (Supplementary Table S2). The average length of the mapped genomes studied was $4,473,412$ base pair (bp). The greatest genome size was 4,528,137 bp (strain NECR70), the smallest genome size was 4,440,985 bp (strain NECR107).

Interestingly, in the two cases, the genome sizes were decreased in the second sample and this decrease was more important for the strain isolated at 9 months (vs. 4 months) 
(-87,152 vs. $-13,374$, respectively) (Table 4). An average of 4280 open-reading frames (ORFs) were predicted.

Variant call analysis showed the presence of SNPs within coding regions, comparing E. coli isolates against wild-type strains (Supplementary Table S3). When evaluating SNPs in NECS50 strain, 1764 nucleotides were identified, and affected 30\% of genes $(1277 / 4284)$, as far as in the case of NECR107 strain, 6874 positions were annotated and dispersed within $51.5 \%$ of ORFs (2198/4267). Only Stop gain mutations were implicated in this analysis and affected genes were analysed depending on its function (virulence factors and other gene). Virulence encoding and non-virulence encoding genes were affected. Putative acyl-CoA dehydrogenase-encoding gene $a i d B$ was the unique gene shared by both strains (results are summarized in Table 5). PAIs were identified within all analysed genomes. A loss of some parts of these regions were noticed when comparing both type NECR107 and NECS50 strains with their wild-type strains (NECR70 and NECS21, respectively) (Figure 2).

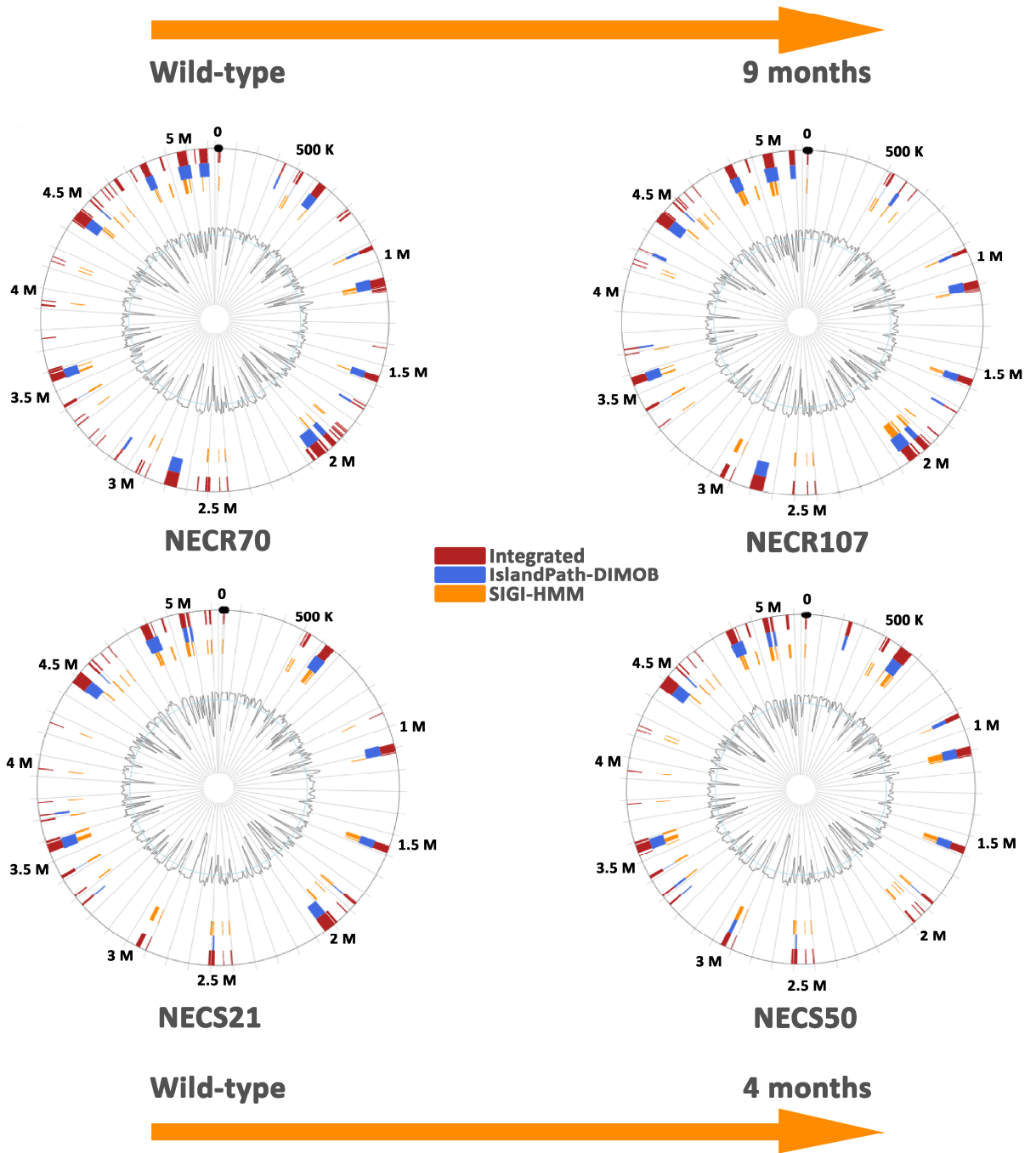

Figure 2. Prediction of pathogenicity islands within Escherichia coli genomes isolated from diabetic foot infections. Pathogenicity islands were predicted using IslandViewer 4, including three predictions methods Integrated, IslandPath-DIMOB, and SIGI-HMM (http: / www.pathogenomics.sfu.ca / islandviewer (accessed on 28 January 2021)). 
Table 5. Comparison between wild-type and target strains based on Stop gain affected genes.

\begin{tabular}{|c|c|}
\hline NECS21/ NECS50 & NECR70/ NECR107 \\
\hline \multicolumn{2}{|c|}{ Genes non-encoding for virulence factors } \\
\hline & Hypothetical protein $(28 \times)$ \\
\hline & Putative acyl-CoA dehydrogenase AidB * \\
\hline & Alanine-tRNA ligase machinerie synthèse prot Guo M Nature 2009 \\
\hline & Allantoinase \\
\hline & Anguibactin system regulator \\
\hline & 8-amino-7-oxononanoate synthase \\
\hline & Multifunctional CCA protein \\
\hline & DNA polymerase IV 1 \\
\hline & Hexuronate transporter \\
\hline & DNA translocase FtsK segregation chromosome \\
\hline & Glycolate permease GlcA transporteur mb \\
\hline & Malate synthase $\mathrm{G}$ \\
\hline & Bifunctional glutamine synthetase \\
\hline & adenylyltransferase/adenylyl-removing enzyme \\
\hline & DNA gyrase subunit B \\
\hline & Oxygen-independent coproporphyrinogen-III oxidase-like protein YqeR \\
\hline & 5-hydroxyisourate hydrolase \\
\hline & Putative defective protein IntQ \\
\hline & Prophage integrase IntS \\
\hline & Aerobactin synthase \\
\hline & Group II intron-encoded protein LtrA \\
\hline & Lactate utilization protein A \\
\hline & System maltose-specific EIICB component \\
\hline & M annosyl-D-glycerate transport/metabolism system MngR \\
\hline & Transcriptional repressor MprA \\
\hline Hypothetical protein $(6 \times)$ & Protein-methionine-sulfoxide reductase catalytic subunit MsrP \\
\hline Putative acyl-CoA dehydrogenase AidB * & Protein-methionine-sulfoxide reductase heme-binding subunit MsrQ \\
\hline Branched-chain-amino-acid aminotransferase & Adenine DNA glycosylase \\
\hline PTS system maltose-specific EIICB component & $\mathrm{Na}+/ \mathrm{H}+$ antiporter $\mathrm{NhaB}$ \\
\hline Sensor histidine kinase YehU & Bifunctional NAD $(\mathrm{P}) \mathrm{H}$-hydrate repair enzyme Nnr \\
\hline Putative lipoprotein YfhM & Oligoribonuclease \\
\hline Inner membrane protein YjiY & Putrescine aminotransferase \\
\hline Pyrimidine 5'-nucleotidase YjjG & Glucose-6-phosphate isomerase \\
\hline & Putative glycerol-3-phosphate acyltransferase \\
\hline & AD-dependent dihydropyrimidine dehydrogenase subunit PreA \\
\hline & Epoxyqueuosine reductase \\
\hline & dITP/XTP pyrophosphatase \\
\hline & 3,4-dihydroxy-2-butanone 4-phosphate synthase \\
\hline & 23S rRNA (guanosine-2'-O-)-methyltransferase RlmB \\
\hline & Ribonuclease $\mathrm{R}$ \\
\hline & 50S ribosomal protein L16 3-hydroxylase \\
\hline & 30S ribosomal protein S6 \\
\hline & 30 S ribosomal protein S18 \\
\hline & Chromosome partition protein Smc \\
\hline & Alpha-ketoglutarate-dependent taurine dioxygenase \\
\hline & tRNA threonylcarbamoyladenosine biosynthesis protein TsaE \\
\hline & $\mathrm{L}(+)$-tartrate dehydratase subunit alpha \\
\hline & Undecaprenyl-diphosphatase \\
\hline & Diguanylate cyclase $\mathrm{YdeH}$ \\
\hline & Putative sensor-like histidine kinase YedV \\
\hline & Putative transcriptional regulatory protein YedW \\
\hline & Flap endonuclease Xni \\
\hline & Putative acid-amine ligase YgiC \\
\hline & 4,5-DOPA dioxygenase extradiol \\
\hline & Inorganic triphosphatase \\
\hline & Sensor histidine kinase YpdA \\
\hline & Inner membrane protein YqiJ intégrité mb \\
\hline & Inner membrane protein YqiK \\
\hline
\end{tabular}


Table 5. Cont.

\begin{tabular}{cc}
\hline NECS21/ NECS50 & NECR70/ NECR107 \\
\hline Genes encoding for virulence factors and stress response \\
\hline Acyl carrier protein & $\begin{array}{c}\text { Multiple stress resistance protein BhsA } \\
\text { Cytoskeleton bundling-enhancing protein CbeA } \\
\text { Chaperone protein DnaJ }\end{array}$ \\
Cytoplasmic alpha-amylase & Type II secretion system protein E \\
2,4-dienoyl-CoA reductase [NADPH] & N-acetyl-alpha-D-glucosaminyl-diphospho-ditrans, \\
Modulator of FtsH protease HflK & Uroporphyrinogen decarboxylase \\
Respiratory nitrate reductase 2 alpha chain & Ascorbate-specific PTS system EIIC component \\
NADH-quinone oxidoreductase subunit G & Ascorbate-specific PTS system EIIA component \\
Epoxyqueuosine reductase & Membrane-bound lytic murein transglycosylase C \\
Cytoplasmic trehalase & Lipopolysaccharide export system permease protein LptF \\
Putative diguanylate cyclase YedQ & Lipopolysacharide export system permease LptG \\
& Polysialic acid transport protein KpsD \\
& Serine protease sat autotransporter
\end{tabular}

Only multidrug transporter $A$ gene $(m d f(A))$ was identified in the four strains, with a coverage of 100\% for all isolates, and an identity varying between 97.57\% (NECR70, NECR107) to $98.14 \%$ (NECS21, NECS50). $m d f(A)$ has a broad-spectrum specificity that include erythromycin, tetracycline, rifampicin, kanamycin, chloramphenicol, and ciprofloxacin. Neither other resistant markers, nor plasmids, were detected.

\section{Discussion}

This study characterised the E. coli strains isolated from DFOM and deep DFI and demonstrated that these bacteria were highly genetically diverse with different pathogenicity traits. Among them, some strains belonged to ST73, a major clonal complex isolated from UTI particularly pyelonephritis and associated with multidrug resistance profile [35-37]. Moreover, these strains were isolated from monomicrobial infection in our panel confirming their virulence potential.

As previously observed for SSTI, the studied strains belonged mainly to ExPEC strains, harboring a higher prevalence of seven known virulence factors. These virulence factors comprised adhesins, iron acquisition systems (e.g., aerobactin synthesis and uptake), and host defense avoidance mechanisms (e.g., cytotoxins, capsule) [38]. This study also highlighted that $E$. coli from diverse origins (with different ST) were capable of causing similar infections. They presented patterns of virulence, genomic and functional properties important in the pathophysiology, even if they were not specifically associated with a pathotype [6]. As also previously observed for E. coli isolated from SSTI [5] and osteomyelitis [39], the majority of the strains belonged to the $\mathrm{B} 2$ and D phylogroups, typically associated with more virulent strains $[5,6,38]$. However, it is interesting to note that some commensal E. coli $(n=6,17 \%)$ belonging to non-B2 and -D phylogroups and which are not ExPEC, can also be isolated in DFOM, demonstrating an environmental adaptation modifying the pathogenicity of the "opportunistic" pathogen and the influence of host immunosuppression. Globally, E. coli strains isolated from DFOM exhibited less VFs than strains involved in deep DFI (Table 3). However, papG2, sfaS and traT genes were more frequently present in B2 strains isolated from deep DFI whereas papG3, irp2 and fyuA genes were more detected in DFOM. Adhesion is mainly due to type I fimbriae $(\mathrm{fimH})$, present in all the strains. This characteristic of our population was not previously found in SSTI [6] but observed in OM [39] suggesting the importance of this adhesin to reach the bone. This is an important point due to the very low ability of E. coli to adhere to osteoblasts [39,40]. The presence of various adhesins could be the way to maintain this bacterium in the infrastructure of the bone, hijacking host defense. In this way, we observed that our strains harboured more papG2 genes compared to other studies on SSTI and OM (40\% vs. $10-20 \%)[5,6]$. Thus, fimH, papG2 and sfa could represent the different solutions developed by E. coli to 
establish infection in bone structure. Siderophore production is also important for bacterial survival [41]. Interestingly, the strains isolated from DFOM harboured a high prevalence of siderophore encoding genes, suggesting the importance to find iron for the bacterial survival and multiplication in this stringent environment (as suggested by [6]). This was associated with the prevalence of $c n f 1$ and $h l y A$ ( $29 \%$ and $34 \%$, respectively), at a level similar to those found among SSTI [5], OM [39] and UTI [42-44]. These two toxins-encoding genes were associated in $75 \%$ of the strains possessing it, because $c n f 1$ and $h l y A$ (among the hemolysin operon $h l y C A B D$ ) were present in the pathogenicity island II (PAI II) J96 [45,46]. The HlyA toxin is particularly important to involve host cell apoptosis or necrosis/lysis (e.g., erythrocytes) and facilitate nutrient acquisition and iron liberation [30]. Crémet et al. highlighted the cytolytic activity of the HlyA against MG-63 osteoblastic cells when it was associated with the other Cnf1 toxin contributing to explain the virulence of our panel strains [39]. Finally, our isolates harboured a high prevalence of kpsMTII, traT, and ompT compared to SSTI or OM previously published $[5,6,39]$. This highlights that these E. coli could produce an important arsenal of "weapons" to avoid host response.

In this study, we determined for the first time the longitudinal evolution of E. coli genomes present at different times in bone. Only two patients $(6 \%$ of our panel) presented this situation, suggesting that this event was rare in DFOM. In these two patients, the late isolate was derived from its early counterpart. For the first patient, E. coli NECR70 and NECR107 belonged to the ST 597, D phylogroup, and were found at nine-month intervals; for the second, E. coli NECS21 and NECS50 belonged to the ST31, D phylogroup, and were found at four-month intervals. The comparative genome analysis showed that the genome content of the strains after some months in bone decreased. This observation is the reverse of the classical genome expansion in E. coli, which is associated with the acquisition of PAIs and VFs by horizontal gene transfer contributing to the development of infections [47]. Here, the bacterial adaptation of a "bone life" involved some genetic rearrangements. The longer the period of this "bone life" was, the more the VFs encoding and non-encoding genes were affected (Table 5). Interestingly, the virulome, the resistome and the housekeeping genes were modified. Thus, we could note the absence of $h l y A$ and cnf1, two genes affecting the virulence as seen above. This suggests that $E$. coli strains modify their virulence by generating an adapted microbial population in the aim to survive in the bone and limit the host immune response as described [48]. Among the two collection strains, only one common gene was mutated: the putative acyl-CoA dehydrogenase AidBencoding gene. AidB is a protein expressed within the Ada response, related in sequence to the acyl-coenzyme A (acyl-CoA) dehydrogenase family (ACADs) [49,50]. The Ada response plays an important role in protecting cells against the cytotoxic and mutagenic action of alkylating agents. This Ada response involves the expression of four genes creating the Ada operon $(a d a, a l k A, a l k B, a i d B)$ that encodes for four proteins (Ada, AlkA, AlkB, AidB) playing specialized functions in removing alkylating lesions from DNA and RNA [49]. An effect of aidB mutation has been observed at low, sublethal doses of alkylating agents, indicating an AidB role in DNA protection against by-products of cell metabolism during stationary phase [51-53]. As the isolated strain (NECR107) at nine months harbored more mutations than the strain (NECS50) isolated at four months (Table 5), we could hypothesize that the deregulation of the Ada operon could cause some cellular abnormalities limiting the repair function of E. coli. Thus, this is interesting to note that E. coli after 9 months had some genome mutations affecting the "machinery" of the bacteria (e.g., Alanine-tRNA ligase-, DNA polymerase-, ribonuclease-encoding genes, $t s a E$, ftsk), the membrane integrity (e.g., glcA, yqiJ, yqiK), and the bacterial virulence (affecting biofilm or stress resistance). Conversely, these mutations increased the bacterial resistance to antibiotics (e.g., gyrB, ygiC). Finally, we could observe genetic modifications on $y d e H, y d d A$, or cytoplasmic alphaamylase encoding gene. The mutations of these genes have been previously associated with bacterial persistence and adaptation to long term survival [54,55], a state clearly observed in our study. 
Finally, a study highlights the link between bacterial traits and host characteristics [14]. The authors showed that in urosepsis, the most virulent isolates were isolated from younger, urological intact women, whereas the less virulent were preferentially isolated from older, urologically compromised men [14]. Furthermore, it has been shown that the prevalence and severity of DFIs are a consequence of host-related processes (e.g., immunopathy, neuropathy, and arteriopathy) and pathogen-related factors (e.g., virulence, antibioticresistance, and microbial organization) [56,57]. We could suggest that this host characteristic of diabetic patients clearly influences the infection and even if some E. coli had low virulence traits, this could be enough to establish a deep infection.

\section{Conclusions}

This study indicates that a majority of ExPEC are responsible of DFOM and deep DFI. The adaptation of E. coli under stressful conditions (in bone cells) could involve a genome reduction and some important modifications in the metabolism and the balance virulence/resistance of the bacteria. This may suggest to clinicians to optimize antibiotic therapy against $E$. coli found in DFI to avoid their implantation in the bone.

Supplementary Materials: The following are available online at https:/ /www.mdpi.com/2076-260 7/9/2/380/s1, Table S1: Ecology of Diabetic Foot Infections during the inclusion period of the study in Nîmes University Hospital, Table S2: Escherichia coli toxin/antitoxin and virulence factors encoding ORF, Table S3: Effect of single-nucleotide polymorphism on Escherichia coli wild-type strains.

Author Contributions: Conceptualization, J.-P.L., A.S. and A.P.; methodology, B.L.S., J.-P.L. and A.P.; software, M.H..; validation, A.S., B.L.S., A.S. and A.P.; formal analysis, A.L., M.H. and J.J.; investigation, S.S., N.C. and A.S.; resources, S.S., N.C. and A.S.; data curation, A.L., M.H., and J.J..; writing—original draft preparation, A.L., M.H., J.-P.L. and A.P.; writing—review and editing, J.J., S.S., N.C., A.S. and B.L.S.; supervision, B.L.S., J.-P.L. and A.P.; project administration, B.L.S., J.-P.L. and A.P.; funding acquisition, A.S., B.L.S. and J.-P.L. All authors have read and agreed to the published version of the manuscript.

Funding: This research was funded by the National Institute of Health and Medical Research (grant number U1047), and the French Government under the "Investissements d'avenir" (Investments for the Future) program managed by the Agence Nationale de la Recherche (ANR, French National Agency for Research) (grant number: Méditerranée Infection 10-IAHU-03). MH and JJ's PhD grant were supported by Fondation de Coopération Scientifique, Méditerranée-Infection (grants from Infectiopole Sud).

Acknowledgments: We thank the Nîmes University hospital for its structural, human, and financial support through the award obtained by our team during the internal call for tenders « Thématiques phares ».

Conflicts of Interest: The authors declare no conflict of interest. The funders had no role in the design of the study; in the collection, analyses, or interpretation of data; in the writing of the manuscript, or in the decision to publish the results.

\section{References}

1. Armstrong, D.G.; Boulton, A.J.M.; Bus, S.A. Diabetic foot ulcers and their recurrence. N. Engl. J. Med. 2017, 376, 2367-2375. [CrossRef] [PubMed]

2. Lipsky, B.A.; Senneville, E.; Abbas, Z.G.; Aragón-Sánchez, J.; Diggle, M.; Embil, J.M.; Kono, S.; Lavery, L.A.; Malone, M.; van Asten, S.A.; et al. Guidelines on the diagnosis and treatment of foot infection in persons with diabetes (IWGDF 2019 update). Diabetes Metab. Res. Rev. 2020, 36, 1-24. [CrossRef]

3. Senneville, E.M.; Lipsky, B.A.; van Asten, S.A.V.; Peters, E.J. Diagnosing diabetic foot osteomyelitis. Diabetes Metab. Res. Rev. 2020, 36, 1-4. [CrossRef]

4. Uçkay, I.; Gariani, K.; Pataky, Z.; Lipsky, B.A. Diabetic foot infections: State-of-the-art. Diabetes Obes. Metab. 2014, 16, 305-316. [CrossRef]

5. Petkovšek, Ž.; Eleršič, K.; Gubina, M.; Žgur-Bertok, D.; Starčič Erjavec, M. Virulence potential of Escherichia coli isolates from skin and soft tissue infections. J. Clin. Microbiol. 2009, 48, 1811-1817. [CrossRef]

6. Ranjan, A.; Shaik, S.; Nandanwar, N.; Hussain, A.; Tiwari, S.K.; Semmler, T.; Jadhav, S.; Wieler, L.H.; Alam, M.; Colwell, R.R.; et al. Comparative genomics of Escherichia coli isolated from skin and soft tissue and other extraintestinal infections. mBio 2017, 8, e01070-17. [CrossRef] [PubMed] 
7. Li, X.; Qi, X.; Yuan, G.; Ju, S.; Yu, Z.; Deng, W.; Liu, Y.; Li, Y.; Bu, X.; Ding, M.; et al. Microbiological profile and clinical characteristics of diabetic foot infection in northern China: A retrospective multicentre survey in the Beijing area. J. Med. Microbiol. 2018, 67, 160-168. [CrossRef]

8. Jain, S.K.; Barman, R. Bacteriological profile of diabetic foot ulcer with special reference to drug-resistant strains in a tertiary care center in North-East India. Indian J. Endocrinol. Metab. 2017, 21, 688-694.

9. Miyan, Z.; Fawwad, A.; Sabir, R.; Basit, A. Microbiological pattern of diabetic foot infections at a tertiary care center in a developing country. J. Pak. Med. Assoc. 2017, 67, 665-669.

10. Hatipoglu, M.; Mutluoglu, M.; Uzun, G.; Karabacak, E.; Turhan, V.; Lipsky, B.A. The microbiologic profile of diabetic foot infections in Turkey: A 20-year systematic review: Diabetic foot infections in Turkey. Eur. J. Clin. Microbiol. Infect. Dis. 2014, 33, 871-878. [CrossRef] [PubMed]

11. Zubair, M.; Malik, A.; Ahmad, J. Incidence, risk factors for amputation among patients with diabetic foot ulcer in a North Indian tertiary care hospital. Foot 2012, 22, 24-30. [CrossRef]

12. Johnson, J.R. Virulence factors in Escherichia coli urinary tract infection. Clin. Microbiol. Rev. 1991, 4, 80-128. [CrossRef]

13. Dobrindt, U. (Patho-)genomics of Escherichia coli. Int. J. Med. Microbiol. 2005, 295, 357-371. [CrossRef]

14. Johnson, J.R.; Porter, S.; Johnston, B.; Kuskowski, M.A.; Spurbeck, R.R.; Mobley, H.L.; Williamson, D.A. Host characteristics and bacterial traits predict experimental virulence for Escherichia coli bloodstream isolates from patients with urosepsis. Open Forum Infect Dis. 2015, 2, ofv083. [CrossRef]

15. World Health Organization. Ethical Principles for Medical Research Involving Human Subjects. World Medical Association Declaration of Helsinki. Bull. WHO 2001, 79, 373-374.

16. Dryden, M.; Lavigne, J.P. Diabetic foot infection. In EMCM, European Manuel of Clinical Microbiology, 1st ed.; ESCMID-SFM Ed.: Paris, France, 2012; Volume 31, pp. 235-240.

17. Clermont, O.; Christenson, J.K.; Denamur, E.; Gordon, D.M. The Clermont Escherichia coli phylo-typing method revisited: Improvement of specificity and detection of new phylo-groups. Environ Microbiol. Rep. 2013, 5, 58-65. [CrossRef] [PubMed]

18. Pitout, J.D.; Hanson, N.D.; Church, D.L.; Laupland, K.B. Population-based laboratory surveillance for Escherichia coli-producing extended-spectrum beta-lactamases: Importance of community isolates with blaCTX-M genes. Clin. Infect. Dis. 2004, 38, 1736-1741. [CrossRef]

19. Rice, L.B.; Carias, L.L.; Hujer, A.M.; Bonafede, M.; Hutton, R.; Hoyen, C.; Bonomo, R.A. High-level expression of chromosomally encoded SHV-1 beta-lactamase and an outer membrane protein change confer resistance to ceftazidime and piperacillintazobactam in a clinical isolate of Klebsiella pneumoniae. Antimicrob Agents Chemother. 2000, 44, 362-367. [CrossRef] [PubMed]

20. Pérez-Pérez, F.J.; Hanson, N.D. Detection of plasmid-mediated AmpC beta-lactamase genes in clinical isolates by using multiplex PCR. J. Clin. Microbiol. 2002, 40, 2153-2162. [CrossRef] [PubMed]

21. Lavigne, J.P.; Bruyère, F.; Bernard, L.; Combescure, C.; Ronco, E.; Lanotte, P.; Coloby, P.; Thibault, M.; Cariou, G.; Desplaces, N.; et al. Resistance and virulence potential of uropathogenic Escherichia coli strains isolated from patients hospitalized in urology departments: A French prospective multicentre study. J. Med. Microbiol. 2016, 65, 530-537. [CrossRef] [PubMed]

22. Czeczulin, J.R.; Whittam, T.S.; Henderson, I.R.; Navarro-Garcia, F.; Nataro, J.P. Phylogenetic analysis of enteroaggregative and diffusely adherent Escherichia coli. Infect. Immun. 1999, 67, 2692-2699. [CrossRef]

23. Johnson, J.R.; Russo, T.A.; Tarr, P.I.; Carlino, U.; Bilge, S.S.; Vary, J.C., Jr.; Stell, A.L. Molecular epidemiological and phylogenetic associations of two novel putative virulence genes, iha and iroN (E. coli), among Escherichia coli isolates from patients with urosepsis. Infect Immun. 2000, 68, 3040-3047. [CrossRef] [PubMed]

24. Johnson, J.R.; Delavari, P.; Kuskowski, M.; Stell, A.L. Phylogenetic distribution of extraintestinal virulence-associated traits in Escherichia coli. J. Infect. Dis. 2001, 183, 78-88. [CrossRef]

25. Wiles, T.J.; Mulvey, M.A. The RTX pore-forming toxin $\alpha$-hemolysin of uropathogenic Escherichia coli: Progress and perspectives. Future Microbiol. 2013, 8, 73-84. [CrossRef] [PubMed]

26. Russo, T.A.; Johnson, J.R. Proposal for a new inclusive designation for extraintestinal pathogenic isolates of Escherichia coli: ExPEC. J. Infect. Dis. 2000, 181, 1753-1754. [CrossRef]

27. Seemann, T. Prokka: Rapid prokaryotic genome annotation. Bioinformatics 2014, 30, 2068-2069. [CrossRef]

28. Zankari, E.; Hasman, H.; Cosentino, S.; Vestergaard, M.; Rasmussen, S.; Lund, O.; Aarestrup, F.M.; Larsen, M.V. Identification of acquired antimicrobial resistance genes. J. Antimicrob. Chemother. 2012, 67, 2640-2644. [CrossRef]

29. Bortolaia, V.; Kaas, R.F.; Ruppe, E.; Roberts, M.C.; Schwarz, S.; Cattoir, V.; Philippon, A.; Allesoe, R.L.; Rebelo, A.R.; Florensa, A.R.; et al. ResFinder 4.0 for predictions of phenotypes from genotypes. J. Antimicrob. Chemother. 2020, 75, 3491-3500. [CrossRef]

30. Carattoli, A.; Zankari, E.; Garcia-Fernandez, A.; Voldby Larsen, M.; Lund, O.; Villa, L.; Aarestrup, F.M.; Hasman, H. In silico detection and typing of plasmids using PlasmidFinder and plasmid multilocus sequence typing. Antimicrob. Agents Chemother. 2014, 58, 3895-3903. [CrossRef] [PubMed]

31. Katoh, K.; Standley, D.M. MAFFT multiple sequence alignment software version 7: Improvements in performance and usability. Mol. Biol. Evol. 2013, 30, 772-780. [CrossRef]

32. Page, A.J.; Taylor, B.; Delaney, A.J.; Soares, J.; Seemann, T.; Keane, J.A.; Harris, S.R. SNP-sites: Rapid efficient extraction of SNPs from multi-FASTA alignments. Microb. Genom. 2016, 2, e000056. [CrossRef] [PubMed] 
33. Cingolani, P.; Platts, A.; Wang, L.L.; Coon, M.; Nguyen, T.; Wang, L.; Land, S.J.; Lu, X.; Ruden, D.M. A program for annotating and predicting the effects of single nucleotide polymorphisms, SnpEff: SNPs in the genome of Drosophila melanogaster strain w1118; iso-2; iso-3. Fly 2012, 6, 80-92. [CrossRef]

34. Bertelli, C.; Laird, M.R.; Williams, K.P.; Simon Fraser University Research Computing Group; Lau, B.Y.; Hoad, G.; Winsor, G.L.; Brinkman, F.S.L. IslandViewer 4: Expanded prediction of genomic islands for larger-scale datasets. Nucleic Acids Res. 2017, 45, W30-W35. [CrossRef]

35. Nüesch-Inderbinen, M.T.; Baschera, M.; Zurfluh, K.; Hächler, H.; Nüesch, H.; Stephan, R. Clonal diversity, virulence potential and antimicrobial resistance of Escherichia coli causing community acquired urinary tract infection in Switzerland. Front Microbiol. 2017, 8, 2334. [CrossRef] [PubMed]

36. Yamaji, R.; Rubin, J.; Thys, E.; Friedman, C.R.; Riley, L.W. Persistent pandemic lineages of uropathogenic Escherichia coli in a college community from 1999 to 2017. J. Clin. Microbiol. 2018, 56, e01834-17. [CrossRef]

37. de Souza da-Silva, A.P.; de Sousa, V.S.; Martins, N.; da Silva Dias, R.C.; Bonelli, R.R.; Riley, L.W.; Moreira, B.M. Escherichia coli sequence type 73 as a cause of community acquired urinary tract infection in men and women in Rio de Janeiro, Brazil. Diagn Microbiol. Infect. Dis. 2017, 88, 69-74. [CrossRef]

38. Micenková, L.; Bosák, J.; Vrba, M.; Ševčíková, A.; Šmajs, D. Human extraintestinal pathogenic Escherichia coli strains differ in prevalence of virulence factors, phylogroups, and bacteriocin determinants. BMC Microbiol. 2016, 16, 218. [CrossRef] [PubMed]

39. Crémet, L.; Broquet, A.; Brulin, B.; Jacqueline, C.; Dauvergne, S.; Brion, R.; Asehnoune, K.; Corvec, S.; Heymann, D.; Caroff, N. Pathogenic potential of Escherichia coli clinical strains from orthopedic implant infections towards human osteoblastic cells. Pathog. Dis. 2015, 73, ftv065. [CrossRef]

40. Fiedler, T.; Salamon, A.; Adam, S.; Herzmann, N.; Taubenheim, J.; Peters, K. Impact of bacteria and bacterial components on osteogenic and adipogenic differentiation of adipose-derived mesenchymal stem cells. Exp. Cell Res. 2013, 319, $2883-2892$. [CrossRef]

41. Braun, V. Iron uptake by Escherichia coli. Front Biosci. 2003, 8, s1409-s1421. [CrossRef]

42. Jaureguy, F.; Landraud, L.; Passet, V.; Diancourt, L.; Frapy, E.; Guigon, G.; Carbonnelle, E.; Lortholary, O.; Clermont, O.; Denamur, E.; et al. Phylogenetic and genomic diversity of human bacteremic Escherichia coli strains. BMC Genom. 2008, 9, 560. [CrossRef]

43. Sannes, M.R.; Kuskowski, M.A.; Owens, K.; Gajewski, A.; Johnson, J.R. Virulence factor profiles and phylogenetic background of Escherichia coli isolates from veterans with bacteremia and uninfected control subjects. J. Infect. Dis. 2004, 190, 2121-2128. [CrossRef] [PubMed]

44. Johnson, J.R.; Stell, A.L. Extended virulence genotypes of Escherichia coli strains from patients with urosepsis in relation to phylogeny and host compromise. J. Infect. Dis. 2000, 181, 261-272. [CrossRef] [PubMed]

45. Schmidt, H.; Hensel, M. Pathogenicity islands in bacterial pathogenesis. Clin. Microbiol. Rev. 2004, 17, 14-56. [CrossRef]

46. Landraud, L.; Gibert, M.; Popoff, M.R.; Boquet, P.; Gauthier, M. Expression of cnf1 by Escherichia coli J96 involves a large upstream DNA region including the hlyCABD operon, and is regulated by the RfaH protein. Mol. Microbiol. 2003, 47, 1653-1667. [CrossRef]

47. Bohlin, J.; Brynildsrud, O.B.; Sekse, C.; Snipen, L. An evolutionary analysis of genome expansion and pathogenicity in Escherichia coli. BMC Genom. 2014, 15, 882. [CrossRef]

48. Marvig, R.L.; Sommer, L.M.; Jelsbak, L.; Molin, S.; Johansen, H.K. Evolutionary insight from whole-genome sequencing of Pseudomonas aeruginosa from cystic fibrosis patients. Future Microbiol. 2015, 10, 599-611. [CrossRef]

49. Mielecki, D.; Grzesiuk, E. Ada response-a strategy for repair of alkylated DNA in bacteria. FEMS Microbiol. Lett. 2014, $355,1-11$. [CrossRef] [PubMed]

50. Landini, P.; Hajec, L.I.; Volkert, M.R. Structure and transcriptional regulation of the Escherichia coli adaptive response gene aidB. J. Bacteriol. 1994, 176, 6583-6589. [CrossRef] [PubMed]

51. Rippa, V.; Duilio, A.; di Pasquale, P.; Amoresano, A.; Landini, P.; Volkert, M.R. Preferential DNA damage prevention by the E. coli aidB gene: A new mechanism for the protection of specific genes. DNA Repair 2011, 10, 934-941. [CrossRef]

52. Volkert, M.R.; Nguyen, D.C.; Beard, K.C. Escherichia coli gene induction by alkylation treatment. Genetics 1986, 112, 11-26. [CrossRef]

53. Landini, P.; Hajec, L.I.; Nguyen, L.H.; Burgess, R.R.; Volkert, M.R. The leucine-responsive regulatory protein (Lrp) acts as a specific repressor for sigma s-dependent transcription of the Escherichia coli aidB gene. Mol. Microbiol. 1996, 20, 947-955. [CrossRef]

54. Zähringer, F.; Massa, C.; Schirmer, T. Efficient enzymatic production of the bacterial second messenger c-di-GMP by the diguanylate cyclase YdeH from E. coli. Appl. Biochem. Biotechnol. 2011, 163, 71-79. [CrossRef] [PubMed]

55. Battesti, A.; Bouveret, E. Acyl carrier proein/SpoT interaction, the switch liking SpoT-dependent stress response to fatty acid metabolism. Mol. Microbiol. 2006, 62, 1048-1063. [CrossRef] [PubMed]

56. Lavery, L.A.; Armstrong, D.G.; Wunderlich, R.P.; Mohler, M.J.; Wendel, C.S.; Lipsky, B.A. Risk factors for foot infections in individuals with diabetes. Diabetes Care 2006, 29, 1288-1293. [CrossRef] [PubMed]

57. Richard, J.L.; Lavigne, J.P.; Sotto, A. Diabetes and foot infection: More than double trouble. Diabetes Metab. Res. Rev. 2012, 28, 46-53. [CrossRef] [PubMed] 